\title{
A historical perspective on ACE2 in the COVID-19 era
}

\author{
Vivek Bhalla $\mathbb{1}^{1,2,3} \cdot$ Catherine A. Blish ${ }^{3,4,5} \cdot$ Andrew M. South $\mathbb{1}^{6,7,8}$
}

Received: 7 June 2020 / Revised: 26 October 2020 / Accepted: 25 November 2020 / Published online: 14 December 2020

(c) The Author(s), under exclusive licence to Springer Nature Limited part of Springer Nature 2020

Coronavirus disease 2019 (COVID-19) is caused by severe acute respiratory syndrome coronavirus 2 (SARS-CoV-2). Lessons learned from severe acute respiratory syndrome coronavirus (SARS-CoV) have facilitated a better understanding of the COVID-19 pandemic and efforts to develop targeted therapies. In particular, COVID-19 reminds us of the importance of the renin-angiotensin-aldosterone system (RAAS) in cardiovascular, pulmonary, and kidney physiology. After decades of RAAS research, we can apply this knowledge to better understand COVID-19 pathophysiology and to inform rigorous studies.

\section{Role of ACE2 in the RAAS}

Angiotensin-converting enzyme 2 (ACE2), a component of the RAAS, was identified as the SARS-CoV binding site [1], and these data facilitated confirmation of the same mechanism for viral entry for SARS-CoV-2, although with 10-20-fold higher affinity [2]. Briefly, the RAAS comprises two major pathways; the first consists of ACE converting angiotensin I (Ang I) into Ang II, which acts at the Ang II type 1 receptor $\left(\mathrm{AT}_{1} \mathrm{R}\right)$ to (1) raise blood pressure via increased renal water and sodium reabsorption and vasoconstriction and (2) stimulate proinflammatory chemokines and endothelial dysfunction [3-5] to promote inflammation. The second is the counter-regulatory arm consisting of

Vivek Bhalla

vbhalla@stanford.edu

1 Stanford Hypertension Center, Stanford University School of Medicine, Stanford, CA, USA

2 Division of Nephrology, Stanford University School of Medicine, Stanford, CA, USA

3 Department of Medicine, Stanford University School of Medicine, Stanford, CA, USA

4 Division of Infectious Diseases and Geographical Medicine, Stanford University School of Medicine, Stanford, CA, USA
ACE2 (60\% homologous to ACE) that utilizes two routes to generate Ang-(1-7) that then acts at the Mas receptor to reduce blood pressure and inflammation [6]. ACE2 primarily metabolizes Ang II into Ang-(1-7) and can also convert Ang I to Ang-(1-9), which is further metabolized by ACE into Ang-(1-7) (Fig. 1A). The balance between these two pathways is a key determinant of both acute and chronic diseases [6], and the beneficial effects of RAAS inhibitors such as ACE inhibitors and $\mathrm{AT}_{1} \mathrm{R}$ blockers (ARBs) are, in part, due to shifting this balance away from ACE-Ang II and toward ACE2-Ang-(1-7) [1, 7].

\section{History of ACE/Ang II and development of RAAS inhibitors}

The physiologic pathway utilized by SARS-CoV-2 was first studied over 100 years ago, and advances in our understanding of the RAAS have accelerated until present day. In 1898, Tigerstedt and Bergman first identified "renin" from kidney extracts that increased blood pressure in rabbits. Further progress was made in 1934, when Goldblatt and colleagues demonstrated that renal artery vasoconstriction, which stimulates renin, induced hypertension [8]. In the mid-1950s, several groups investigated the end-product of renin activity [9, 10], Elliott and Peart characterized a "hypertensin" or "angiotonin" by incubating renin from

5 Chan Zuckerberg Biohub, San Francisco, CA, USA

6 Section of Nephrology, Department of Pediatrics, Brenner Children's Hospital, Wake Forest School of Medicine, Winston Salem, NC, USA

7 Department of Surgery-Hypertension and Vascular Research, Wake Forest School of Medicine, Winston Salem, NC, USA

8 Department of Epidemiology and Prevention, Division of Public Health Sciences, Wake Forest School of Medicine, Winston Salem, NC, USA 


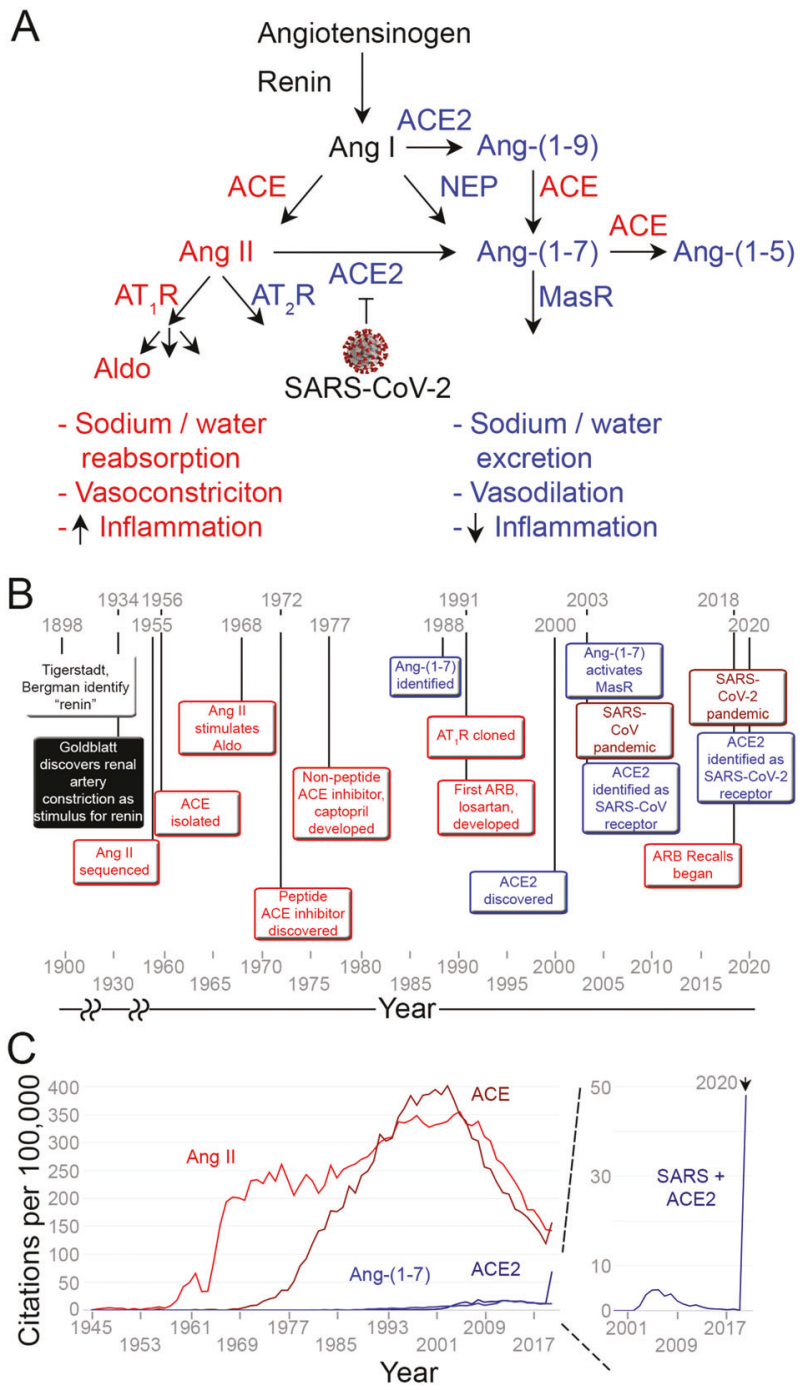

Fig. 1 Historical context of the renin-angiotensin-aldosterone system and coronavirus. A Role of counter-regulatory effects of the ACE2-Ang-(1-7) pathway (blue) in the context of pathologic effects of the ACE-Ang II pathway (red). ACE2 is the receptor for SARS$\mathrm{CoV}$ and SARS-CoV-2, which may decrease ACE2 cell surface expression after binding. B Timeline of discoveries of the RAAS. C Annual PubMed ${ }^{\circledR}$ citations for the two RAAS pathways and SARS (source: https://esperr.github.io/pubmed-by-year/). Ang angiotensin, Aldo Aldosterone, ACE angiotensin-converting enzyme, ACE2 angiotensin-converting enzyme 2, NEP neprilysin, $\mathrm{AT}_{1} \mathrm{R}$ angiotensin II type 1 receptor, $\mathrm{AT}_{2} \mathrm{R}$ angiotensin II type 2 receptor, MasR Mas receptor, SARS severe acute respiratory distress syndrome, $\mathrm{CoV}$ coronavirus.

rabbit kidney with 200 liters of ox sera and quantifying the rise in blood pressure from various eluates. The decapeptide that they isolated and sequenced became known as Ang I [9] and the octapeptide hypertensin II or Ang II [11]. Skeggs and Shumway then isolated the 'hypertensin' converting enzyme, later renamed ACE, from equine plasma by ammonium sulfate fractionation and isoelectric precipitation [12]. This first arm of the RAAS was further defined in
1961 when Genest et al. reported an increase in aldosterone production in medical students and other volunteers upon infusion of Ang II [13], temporarily referred to as aldosterone-secreting hormone. The last link of this pathway, the receptor for Ang II, $\mathrm{AT}_{1} \mathrm{R}$, was identified and cloned in 1991 by two laboratories [14, 15].

Collaborations between academia and industry led to the creation of RAAS inhibitors. Chemists and biologists sped forward to identify the first ACE inhibitors as peptides from the venom of the Brazilian viper Bothrops jararaca. Characterization of these peptides in 1972 facilitated discovery of captopril in 1977 [16]. These contributions led to several novel compounds to treat hypertension, cardiovascular disease, and kidney disease and solidified the importance of the RAAS for human health. ARBs were pursued due to concerns of off-target effects of ACE inhibitors (e.g., increased bradykinin) and potential for nonspecific inhibition of Ang II-mediated $\mathrm{AT}_{2} \mathrm{R}$ activation. Innovators within the pharmaceutical industry resurrected initial, low-affinity agonists to generate losartan in the early 1990s [17, 18], one of the first examples of rational drug design. Many ARBs have since been approved for the treatment of heart failure, hypertension, and chronic kidney disease [8].

In 2018, after 20+ years of efficacy, RAAS inhibitors came under scrutiny. ACE inhibitors were associated with a higher risk of lung cancer [19], and due to impurities detected in several ARBs manufactured in China, India, and elsewhere, the Food and Drug Administration recalled over 20 ARB formulations. After these recalls, regulatory agencies, patients, and healthcare providers have struggled for months to right the ship by instituting routine screening of drugs manufactured outside the US, changing medicines to account for side effects, and restoring trust in the medical system [20]. Despite recent events, ACE inhibitors and ARBs are still considered first-line therapy.

\section{History of ACE2/Ang-(1-7) and development of ACE2-related therapeutics}

The paradigm of this apparently linear pathway was redefined by the discovery of Ang-(1-7) as a by-product of Ang I and Ang II in the late 1980s and early 1990s, and the effects of Ang-(1-7), originally described in brain, were found to be in direct opposition to Ang II [21-23]. More recently, additional pieces of the puzzle have been elucidated. ACE2 was identified as a component of the counterregulatory arm of the RAAS in 2000 by two separate groups $[24,25]$. Defined by comparison to its homolog, ACE, ACE2 was characterized as an ACE-inhibitor-insensitive monocarboxypeptidase that cleaves Ang I and Ang II. Although Ang-(1-7) was known to act via a different pathway than Ang II [26], the molecular mechanism was 
finally identified in 2003. Santos et al. discovered that the Mas receptor, a G-protein-coupled receptor, was the primary conduit for the counter-regulatory arm of the RAAS $[27,28]$. Further studies demonstrated that Mas receptor antagonists can inhibit actions of Ang-(1-7) [26, 29]. These discoveries, that completed the picture of a more complex RAAS, were contemporaneous with the first coronavirus epidemic due to SARS-CoV [30]. Within a few months, ACE2 was identified as the host receptor for SARS-CoV, and the counter-regulatory arm took on a heightened significance for public health [31] (Fig. 1B).

Much like the status of the ACE-Ang II pathway in the 1970s, no definitive therapeutics that target the ACE2Ang-(1-7) have been approved. A-779 and D-pro 7 -Ang(1-7) have been characterized as Mas receptor antagonists in pre-clinical models, but to further counteract the ACEAng II pathway, various groups focused on activation of the ACE2-Ang-(1-7) arm. These include ACE2 activators, bioavailable Ang-(1-7) formulations, and Mas receptor agonists [32]. While these therapeutics have had success in vitro and in pre-clinical animal models, none have progressed to clinical trials. In contrast, recombinant ACE2 was well tolerated in a Phase 1 study in healthy subjects and has been employed under a compassionate use protocol in a patient with COVID-19 [33]. Infusion of ACE2 predictably altered circulating Ang II and Ang-(1-7) but did not significantly change blood pressure or heart rate [34].

\section{The potential roles of the RAAS and related therapeutics in COVID-19}

In 2020, the rapid spread of SARS-CoV-2 has made us again reflect on the risk/benefit ratio of these important drug classes and their mechanisms of action. Based on the interaction between SARS-CoV-2 and ACE2, many postulated that possible RAAS inhibitor-induced ACE2 expression and thus viral propagation could be an important mechanism for the apparent associations between SARSCoV-2 infection and COVID-19 severity and hypertension, cardiovascular disease, and chronic kidney disease. On the other hand, ACE inhibitors and ARBs may be novel therapeutic agents to treat patients with COVID-19 by shifting the RAAS back toward the ACE2-Ang-(1-7)Ang-(1-7) pathway [35]. Several, albeit limited, observational studies have not shown an association between severity of COVID19 with use of ACE inhibitors or ARBs [36-38]. Furthermore, a recent experimental study in mice demonstrated that ACE inhibitors and ARBs do not alter ACE2 activity in lung-isolated epithelial cell membranes [39]. These issues initially generated significant controversy in the public domain and spurred multiple medical societies to urge caution until additional data are available. Of note, randomized clinical trials (NCT04311177, NCT04312009, NCT04338009, and NCT04394117) are ongoing to better address these questions. For example, REPLACECOVID (NCT04338009) is a study of clinical outcomes in patients with COVID-19 with prior outpatient therapy with ACE inhibitors or ARBs with randomization to elimination or prolongation of these drugs and CLARITY (NCT04394117) is a study of ARBs for the treatment of COVID-19.

The recent significance for further research on ACE2 physiology has risen in two related but distinct ways: [1] in its role as a receptor, understanding the regulation of ACE2 cell surface expression to mitigate SARS-CoV-2 entry into host cells; and [2] in its role as a monocarboxypeptidase to generate Ang-(1-7), understanding the consequences of decreased ACE2 expression and function to assess its contribution to hemodynamics, cardiovascular disease, lung function, and kidney disease in patients with COVID-19. As was demonstrated in an animal model of SARS-CoV [1], SARS-CoV-2 may suppress ACE2 expression through internalization, shedding, and downregulation, which would predict diminished Ang-(1-7) production and a subsequent shift toward Ang II- $\mathrm{AT}_{1} \mathrm{R}$-mediated severe acute lung injury and development of fibrosis. As yet, this remains theoretical, and we do not know whether ACE2 expression decreases in COVID-19 and in what tissues this may occur. Moreover, we do not know whether and to what extent tissue (e.g., lung) injury is mediated by Ang II- $\mathrm{AT}_{1} \mathrm{R}$ in COVID-19. Also, whether modulation of ACE2 expression would be beneficial and the timing of such modulation (i.e., before or after interaction with SARS-CoV-2) is unknown. Although additional research on the fate of ACE2 expression and function is needed, recombinant ACE2 has been redeployed in an ongoing Phase 2 clinical trial to test its efficacy in patients with COVID-19 (NCT04335136). The rationale behind this study is to utilize circulating ACE2 as both a monocarboxypeptidase, its endogenous function, and as a decoy receptor to prevent entry of SARS-CoV-2 into host cells. An alternate strategy has employed ACE2derived peptides in vitro to compete with cell surface ACE2 for binding to SARS-CoV-2 [40, 41]. This would theoretically obviate considerations of drug-related changes in ACE2 expression or changes in ACE2 expression or function upon infection, which could have potentially serious ramifications.

\section{An opportunity to restore balance}

SARS-CoV-2 has resurrected the importance of ACE2, including its role in viral transmission and in acute and chronic disease. This pandemic is also a reminder of the importance of basic and clinical research. Our ability to understand the pathophysiology of COVID-19 is 
strengthened by work over the past two decades that outlined the physiologic significance of ACE2 and Ang-(1-7), even though no pharmacologic targets as of now have reduced cardiovascular events.

While we have learned much about the RAAS, our attention, as captured by citations in the literature, has leaned predominantly to one side of the pathway. ACE2related studies, although of crucial importance to hypertension, cardiology, nephrology, and lung physiology, existed in relative obscurity compared to ACE (Fig. 1C). We still understand little about circulating and tissue ACE2 -Ang-(1-7) expression and function and how ACE inhibitors and ARBs affect this pathway in various compartments. Akin to the initial exposure to an antigen, ACE2related citations increased after the discovery of its role as the receptor for SARS-CoV after the SARS epidemic. However, the rate of published ACE2 studies quickly declined back to baseline. Unfortunately, no ACE2-centered therapeutics were approved that could now reduce SARS$\mathrm{CoV}-2$ transmission or COVID-19 progression. ACE2 was identified as the viral binding site less than two months after the first case reports of COVID-19, and again, akin to a secondary immune response, ACE2-related publications have skyrocketed in the past few months and clinical trials for ACE2-related therapeutics have begun. After the last pandemic, we are scientifically primed to focus on ACE2, and as a scientific community we are better prepared to target the ACE2-Ang-(1-7) pathway during and after this pandemic.

\section{Compliance with ethical standards}

Conflict of interest The authors declare that they have no conflict of interest.

Publisher's note Springer Nature remains neutral with regard to jurisdictional claims in published maps and institutional affiliations.

\section{References}

1. Kuba K, Imai Y, Rao S, Gao H, Guo F, Guan B, et al. A crucial role of angiotensin converting enzyme 2 (ACE2) in SARS coronavirus-induced lung injury. Nat Med. 2005;11:875-9.

2. Wrapp D, Wang N, Corbett KS, Goldsmith JA, Hsieh CL, Abiona O, et al. Cryo-EM structure of the 2019-nCoV spike in the prefusion conformation. Science. 2020;367(6483):1260-3.

3. El Bekay R, Alvarez M, Monteseirin J, Alba G, Chacon P, Vega A, et al. Oxidative stress is a critical mediator of the angiotensin II signal in human neutrophils: involvement of mitogen-activated protein kinase, calcineurin, and the transcription factor NFkappaB. Blood. 2003;102:662-71.

4. Garrido AM, Griendling KK. NADPH oxidases and angiotensin II receptor signaling. Mol Cell Endocrinol. 2009;302:148-58.

5. Silva-Filho JL, Souza MC, Henriques M, Morrot A, Savino W, Nunes MP, et al. AT1 receptor-mediated angiotensin II activation and chemotaxis of T lymphocytes. Mol Immunol. 2011;48: 1835-43.

6. South AM, Shaltout HA, Washburn LK, Hendricks AS, Diz DI, Chappell, Mark C. Fetal programming and the angiotensin-(1-7) axis: a review of the experimental and clinical data. Clin Sci. 2019;133:55-74.

7. Patel VB, Bodiga S, Fan D, Das SK, Wang Z, Wang W, et al. Cardioprotective effects mediated by angiotensin II type 1 receptor blockade and enhancing angiotensin 1-7 in experimental heart failure in angiotensin-converting enzyme 2-null mice. Hypertension. 2012;59:1195-203.

8. Timmermans PB, Wong PC, Chiu AT, Herblin WF, Benfield P, Carini DJ, et al. Angiotensin II receptors and angiotensin II receptor antagonists. Pharm Rev. 1993;45:205-51.

9. Elliott DF, Peart WS. Amino-acid sequence in a hypertensin. Nature. 1956;177:527-8.

10. Skeggs LT Jr, Marsh WH, Kahn JR, Shumway NP. Amino acid composition and electrophoretic properties of hypertensin I. J Exp Med. 1955;102:435-40.

11. Lentz KE, Skeggs LT, Woods KR, Kahn JR, Shumway NP. The amino acid composition of hypertensin-ii and its biochemical relationship to hypertensin-I. J Exp Med. 1956;104:183-91.

12. Skeggs LT Jr, Kahn JR, Shumway NP. The preparation and function of the hypertensin-converting enzyme. J Exp Med. 1956;103:295-9.

13. Genest J, Biron P, Koiw E, Nowaczynski W, Boucher R, Chretien M. Studies of the pathogenesis of human hypertension. The adrenal cortex and renal pressor mechanism. Ann Intern Med. 1961;55:12-28.

14. Murphy TJ, Alexander RW, Griendling KK, Runge MS, Bernstein $\mathrm{KE}$. Isolation of a cDNA encoding the vascular type-1 angiotensin II receptor. Nature. 1991;351:233-6.

15. Sasaki K, Yamano Y, Bardhan S, Iwai N, Murray JJ, Hasegawa $\mathrm{M}$, et al. Cloning and expression of a complementary DNA encoding a bovine adrenal angiotensin II type-1 receptor. Nature. 1991;351:230-3.

16. Cushman DW, Ondetti MA. History of the design of captopril and related inhibitors of angiotensin converting enzyme. Hypertension. 1991;17:589-92.

17. Blankley CJ, Hodges JC, Klutchko SR, Himmelsbach RJ, Chucholowski A, Connolly CJ, et al. Synthesis and structure-activity relationships of a novel series of non-peptide angiotensin II receptor binding inhibitors specific for the AT2 subtype. J Med Chem. 1991;34:3248-60.

18. Duncia JV, Carini DJ, Chiu AT, Johnson AL, Price WA, Wong PC, et al. The discovery of DuP 753, a potent, orally active nonpeptide angiotensin II receptor antagonist. Med Res Rev. 1992;12:149-91.

19. Hicks BM, Filion KB, Yin H, Sakr L, Udell JA, Azoulay L. Angiotensin converting enzyme inhibitors and risk of lung cancer: population based cohort study. BMJ. 2018;363:k4209.

20. Byrd JB, Chertow GM, Bhalla V. Hypertension hot potatoanatomy of the angiotensin-receptor blocker recalls. N Engl J Med. 2019;380:1589-91.

21. Benter IF, Ferrario CM, Morris M, Diz DI. Antihypertensive actions of angiotensin-(1-7) in spontaneously hypertensive rats. Am J Physiol. 1995;269:H313-9.

22. Campagnole-Santos MJ, Diz DI, Santos RA, Khosla MC, Brosnihan KB, Ferrario CM. Cardiovascular effects of angiotensin-(17) injected into the dorsal medulla of rats. Am J Physiol. 1989;257:H324-9.

23. Chappell MC, Brosnihan KB, Diz DI, Ferrario CM. Identification of angiotensin-(1-7) in rat brain. Evidence for differential processing of angiotensin peptides. J Biol Chem. 1989;264: $16518-23$. 
24. Donoghue M, Hsieh F, Baronas E, Godbout K, Gosselin M, Stagliano N, et al. A novel angiotensin-converting enzyme-related carboxypeptidase (ACE2) converts angiotensin I to angiotensin 19. Circ Res. 2000;87:E1-9.

25. Tipnis SR, Hooper NM, Hyde R, Karran E, Christie G, Turner AJ. A human homolog of angiotensin-converting enzyme. Cloning and functional expression as a captopril-insensitive carboxypeptidase. J Biol Chem. 2000;275:33238-43.

26. Santos RA, Campagnole-Santos MJ, Baracho NC, Fontes MA, Silva LC, Neves LA, et al. Characterization of a new angiotensin antagonist selective for angiotensin-(1-7): evidence that the actions of angiotensin-(1-7) are mediated by specific angiotensin receptors. Brain Res Bull. 1994;35:293-8.

27. Santos RA, Simoes e Silva AC, Maric C, Silva DM, Machado RP, De Buhr I, et al. Angiotensin-(1-7) is an endogenous ligand for the $G$ protein-coupled receptor Mas. Proc Natl Acad Sci USA. 2003;100:8258-63.

28. Von Bohlen und Halbach O, Walther T, Bader M, Albrecht D. Interaction between Mas and the angiotensin AT1 receptor in the amygdala. J Neurophysiol. 2000;83:2012-21.

29. Santos RA, Haibara AS, Campagnole-Santos MJ, Simoes e Silva AC, Paula RD, Pinheiro SV, et al. Characterization of a new selective antagonist for angiotensin-(1-7), D-pro7-angiotensin-(17). Hypertension. 2003;41:737-43.

30. Drosten C, Gunther S, Preiser W, van der Werf S, Brodt HR, Becker S, et al. Identification of a novel coronavirus in patients with severe acute respiratory syndrome. $\mathrm{N}$ Engl $\mathrm{J}$ Med. 2003;348:1967-76

31. Li W, Moore MJ, Vasilieva N, Sui J, Wong SK, Berne MA, et al. Angiotensin-converting enzyme 2 is a functional receptor for the SARS coronavirus. Nature 2003;426:450-4.
32. Fraga-Silva RA, Ferreira AJ, Dos Santos RA. Opportunities for targeting the angiotensin-converting enzyme 2/angiotensin-(1-7)/ mas receptor pathway in hypertension. Curr Hypertens Rep. 2013;15:31-8.

33. Zoufaly A, Poglitsch M, Aberle JH, Hoepler W, Seitz T, Traugott $\mathrm{M}$, et al. Human recombinant soluble ACE2 in severe COVID-19. Lancet Respir Med. 2020;8(11):1154-8.

34. Haschke M, Schuster M, Poglitsch M, Loibner H, Salzberg M, Bruggisser $\mathrm{M}$, et al. Pharmacokinetics and pharmacodynamics of recombinant human angiotensin-converting enzyme 2 in healthy human subjects. Clin Pharmacokinet. 2013;52:783-92.

35. Sparks MA, South A, Welling P, Luther JM, Cohen J, Byrd JB, et al. Sound science before quick judgement regarding RAS blockade in COVID-19. Clin J Am Soc Nephrol. 2020;15:714-6.

36. Mancia G, Rea F, Ludergnani M, Apolone G, Corrao G. Reninangiotensin-aldosterone system blockers and the risk of Covid19. N. Engl J Med. 2020;382:2431-40.

37. Reynolds HR, Adhikari S, Pulgarin C, Troxel AB, Iturrate E, Johnson SB, et al. Renin-angiotensin-aldosterone system inhibitors and risk of Covid-19. N. Engl J Med. 2020;382:2441-8.

38. Curfman G. Renin-Angiotensin-Aldosterone Inhibitors and Susceptibility to and Severity of COVID-19. JAMA. 2020;324 (2):177-8.

39. Wysocki J, Lores E, Ye M, Soler MJ, Batlle D. Kidney and Lung ACE2 Expression after an ACE Inhibitor or an Ang II Receptor Blocker: Implications for COVID-19. J Am Soc Nephrol. 2020;31 (9):1941-3.

40. Peter EK, Schug A. The Inhibitory Effect of a Coronavirus Spike Protein Fragment with ACE2. Biophys J. 2020.

41. Han Y, Kral P. Computational design of ACE2-based peptide inhibitors of SARS-CoV-2. ACS Nano. 2020;14:5143-7. 